\title{
Association between potential parental and peers' correlates and physical activity recommendations compliance among 13-16 years old adolescents
}

\author{
Peter Bakalár ${ }^{1, *}$, Jaroslava Kopčáková ${ }^{2}$, and Andrea Madarasová Geckováa ${ }^{2,3}$ \\ ${ }^{1}$ Institute of Physical Education and Sport, Pavol Jozef Šafárik University in Košice, Slovakia; ${ }^{2}$ Faculty of Medicine, Pavol \\ Jozef Šafárik University in Košice, Slovakia; and ${ }^{3}$ Olomouc University Social Health Institute, Palacký University Olomouc, \\ Olomouc, Czech Republic
}

Copyright: (C) 2018 P. Bakalár et al. This is an open access article licensed under the Creative Commons Attribution License (https://creativecommons.org/licenses/by/4.0/).

Background: Regular physical activity (PA) is one of the most cited health protective factors for the prevention of the leading noncommunicable diseases. Four-fifths of adolescents are not reaching public health guidelines for recommended levels of PA globally. Understanding factors that influence PA can aid the design of more effective interventions. Objective: The aim of the study was to assess the association between potential parental and peer correlates and PA recommendations compliance among 13-16 years old adolescents. Methods: We used nationally representative data originated from the Health Behaviour in School-aged Children survey realized in 2014 in Slovakia. Data were obtained by questionnaires measuring potential parental and peers' correlates. Gender differences were assessed using chi square test. The associations between potential parental or peers' correlates and moderate-to-vigorous PA (MVPA) of adolescents were explored using logistic regression models adjusted for gender, age, and family affluence. Interaction of the effect of each parental and peer correlate with gender on MVPA was tested. Results: Prevalence of sufficient MVPA was higher among boys than among girls $(p<.001)$. Boys reported more frequently than girls that their best friend does sport every week or that they used to play sport with parents at least once a week $(p<.001)$. All explored variables representing potential parental and peers' correlates were significantly associated with sufficient MVPA of adolescents. However, only the association of a best friend and father doing sport every week and playing sport with parents remained significantly associated with sufficient MVPA of adolescents in mutually adjusted model. Conclusion: Our findings indicate that best friends and fathers may play role in PA behaviour of adolescents through behaviour modelling, and parents in general through tangible parental support (playing sport with children).

Keywords: physical activity, support, modelling, father, best friend

\section{Introduction}

Regular physical activity (PA) is one of the most cited health protective factors for the prevention of the leading noncommunicable diseases (e.g., cardiovascular diseases, diabetes mellitus, cancer, obesity, depression, dementia; World Health Organization [WHO], 2018). In adolescence, PA contributes to healthy development of musculoskeletal system, cardiovascular system and maintenance of optimal body weight (Iannoti et al., 2009). It is also associated with psychological and social benefits, e.g., higher psychological

\footnotetext{
* Address for correspondence: Peter Bakalár, Institute of Physical Education and Sport, Pavol Jozef Šafárik University in Košice, Ondavská 21, 04011 Košice, Slovakia. E-mail: peter.bakalar@upjs.sk
}

well-being or life satisfaction and lower social anxiety (Badura, Madarasova Geckova, Sigmundova, van Dijk, \& Reijneveld, 2015; Biddle \& Mutrie, 2008). WHO (2010) recommends that children and youth aged 5-17 should accumulate at least 60 minutes of moderate-to-vigorous intensity PA (MVPA) daily. The dose-response relations observed in observational studies in children and adolescents indicate that the more PA, the greater the health benefit (Janssen \& LeBlanc, 2010). On contrary, sedentary behaviour and poor physical fitness in adolescence are associated with poor health outcomes (Brindova et al., 2015). Moreover, there are consistent findings in literature indicating decline of PA during adolescence (Dumith, Gigante, Domingues, \& Kohl, 2011; Sigmundová, Sigmund, Hamrik, \& Kalman, 2014). Based on longitudinal studies (Farooq et al., 2018; Reilly, 2016), 
this decline starts in the transition from preschool to school age and result in four-fifths of adolescents not reaching public health guidelines for recommended levels of PA globally (Hallal et al., 2012).

What is generally agreed upon is that no single factor explains PA levels among adolescents or predicts the decline in PA as children age fully, but the reasonable approach is to examine multilevel influences on PA (Hearst, Patnode, Sirard, Farbakhsh, \& Lytle, 2012). Family is considered the most important setting for shaping children's PA (Timperio et al., 2013). Parental correlates of child and adolescent PA could be divided in parental modelling (e.g., parental PA) and parental support (e.g., doing sport together, going for walk together; Yao \& Rhodes, 2015). Because systematic reviews have demonstrated inconclusive evidence on the influence of parental modelling on children's PA, more research is needed in this field (Jaeschke et al., 2017). Unlike the findings for parental modelling and child PA, parental support has emerged as a consistent correlate of child and adolescent PA in a number of narrative reviews (Yao \& Rhodes, 2015).

Peers/best friends (similarly as parents) have a social influence on adolescents' level of PA (Cheng, Mendonça, \& Farias Júnior, 2014) through different types of peer support for PA including instrumental and direct support (e.g., peers or friends participating in PA with adolescent); emotional and motivational support (e.g., peers providing encouragement or praise for PA); or observational support (e.g., peer modelling of PA; Fitzgerald, Fitzgerald, \& Aherne, 2012). From early to late adolescence, support for PA from the family and/or support from friends may result in higher levels of total and discretionary MVPA (Morrisey, Janz, Letuchy, Francis, \& Levy, 2015). Because it seems having active friends encourages PA and having inactive friends discourage it (Maturo \& Cunningham, 2013), peers and friends need to be involved in adolescents' PA in variety of ways if adolescents are to lead physically active lifestyles (Fitzgerald et al., 2012). Even though the use of friendships to promote PA in experiments or interventions remains largely unexplored, findings from observational studies suggest that friends have potential to affect PA and that friendships may offer opportunities to promote the early development of healthy PA habits and preferences that can translate into lifelong habits (Maturo \& Cunningham, 2013).

Prevalence of PA as well as factors influencing establishment of active life style in adolescence might differ by age, gender or family affluence (Inchley et al., 2016; Kopcakova et al., 2015). Younger adolescents, adolescent girls and adolescents from more affluent families are more likely to achieve the recommended 60 minutes of MVPA daily in comparison to older adolescents, adolescent boys and adolescents from less affluent families respectively (Inchley et al., 2016).

The aim of the study was to assess the association between potential parental and peer correlates and PA recommendations compliance (PARC) among 13-16 years old adolescents by using nationally representative data on Slovak school-aged children originated from the Health Behaviour in School-aged Children survey carried out in 2014.

\section{Methods}

\section{Sample and procedure}

We used data from the Health Behaviour in Schoolaged Children (HBSC) study conducted in April-June 2014 in Slovakia. To obtain a representative sample of sufficient size (1,500 respondents per age group), we used a two-step sampling. In the first step, 151 larger and smaller elementary schools located in rural as well as in urban areas from all regions of Slovakia were asked to participate. These were randomly selected from a list of all eligible schools in Slovakia obtained from the Slovak Institute of Information and Prognosis for Education. School response rate was $86.1 \%$. In the second step, one class per each grade and each school were selected randomly. We obtained data from 9,250 adolescents from the fifth to ninth grades of elementary schools in Slovakia in the target group of 11 to 15 years old (mean age 13.48; 50.3\% boys). Questionnaires measuring potential parental and peers' correlates were included only in version A of questionnaire for 13 and 15 years old, and therefore we included only respondents filling this version, which reduced sample to 3,109 respondents. Version A and B were distributed to school classes randomly. Respondents with missing data on age $(n=26)$, younger than 12.5 or older than 16.0 years old $(n=97)$ were excluded from the sample. The final sample consisted of 3,012 respondents from 12.5 to 16.0 years old, $50.2 \%$ boys, mean age 14.3 $(S D=0.85)$ years.

The study was approved by the Ethics Committee of the Medical Faculty at the Pavol Jozef Šafárik University in Košice (No. 9/2012). Parents were informed about the study via the school administration and could opt out if they disagreed with their child's participation. Participation in the study was fully voluntary and anonymous with no explicit incentives provided for participation.

\section{Measures \\ MVPA was measured by an item asking adolescents about the number of days over the past week that they were physically active for a total of at least 60 minutes}


per day. The question was preceded by an explanatory text that defined MVPA as 'any activity that increases your heart rate and makes you get out of breath some of the time' and offered examples of such activities (running, inline skating, cycling, dancing, swimming, ice skating etc.; Inchley et al., 2016). Responses concerned 0 to 7 days per week and were classified as sufficient (PA of 7 days) vs. insufficient (PA less than 7 days), based on the WHO recommendation (WHO, 2010). The MVPA item was adapted for use in the HBSC study from the item developed by Prochaska, Sallis, and Long (2001) for the purposes of clinical practice with adolescents. The authors validated it against seven-day continuous measurement using an accelerometer $(r=.40$, $p<.001)$ and observed its substantial test-retest stability (intraclass correlation coefficient $=.77$; Inchley, Currie, Cosma, \& Samdal, 2018).

Parental and peers' $P A$ were measured by an item asking adolescents if their father, mother, and best friend do sport every week (yes/no).

Parental support was measured using two items of Family Activities Questionnaire (Sweeting, West, \& Richards, 1998). Despite each of 8 family activities (Watch TV or a video together/Play indoor games together/Play computer games together/Eat a meal together/Go for a walk together/Go places together/Visit friends or relatives together / Play sports together / Sit and talk about things together) might be related to health-related behaviour of adolescents as the association between parental time invested in young people and adolescents health development is strong (Brooks, Magnusson, Klemera, Spencer, \& Morgan, 2011), we decided to select only two of them - go for a walk together and play sport together - representing mutual PA, e.g., direct parental support of PA. Respondents could select from five response categories, which were trichotomised as follows: (1) everyday, most days, about once a week; (2) less often; (3) never.

Family affluence was measured by Family Affluence Scale (FAS) which consists of 6 items: (1) car ownership (Does your family own car, van or truck?); (2) own bedroom (Do you have your own bedroom for yourself); (3) computer ownership (How many computers do your family own?); (4) bathrooms (How many bathrooms are in your home?); (5) dishwasher (Does your family have dishwasher at home?); (6) holidays (How many times did you or your family travel out of for a holiday/vacation last year?).

We converted the FAS summary scores to a final score, which has a consistent, normal distribution and a range from 0 to 1 . We then created groups of low (0 to .333), middle (.334 to .666) and high (.667 to 1) socio-economic position. Several studies indicated sufficient validity and reliability of used measurements (Inchley, Currie, Cosma, \& Samdal, 2018).

\section{Statistical analyses}

In the first step, we described the sample using descriptive statistics. Gender differences were assessed using a chi square test. Next, the associations between potential parental or peers' correlates and MVPA of adolescents were explored separately using logistic regression models adjusted for gender (Model 1). Interaction of the effect of each parental and peer correlate with gender on MVPA was tested as well. Then, the association of all potential parental or peers' correlates with MVPA of adolescents was explored using multivariate logistic regression adjusted for gender (Model 2). Finally, this model was adjusted for age and family affluence (Model 3). All data were analysed using IBM SPSS Statistics (Version 20.0 for Windows; IBM, Armonk, NY, USA). Statistical significance was assumed for $p<.05$.

\section{Results}

Only one fifth of respondents reported sufficient MVPA (Table 1). One third of them reported that their mother or father does sport every week and more than $65 \%$ reported that their best friend does sport every week. More than $40 \%$ of adolescents reported that they never play sport with parents and $24 \%$ of them reported that they never go for a walk with parents. The prevalence of sufficient MVPA was higher among boys than among girls $\left(\chi^{2}: 67.39, p<.001\right)$. Moreover, boys reported more frequently than girls that their best friend does sport every week or that they used to play sport with parents at least once a week $\left(\chi^{2}: 59.68 / 29.63\right.$ respectively, $p<.001$ for both outcomes). No gender differences were confirmed in parental PA or joint walks (Figure 1).

All explored variables representing potential parental and peers' correlates were significantly associated with sufficient MVPA of adolescents (Table 2, Model 1; Figure 2). Interaction of the effect of each parental and peer correlate with gender on MVPA was tested, but only in one case found significant. The association between a best friend doing sport every week and sufficient MVPA was significantly steeper/stronger in boys in comparison to girls: odds ratio $1.57,95 \%$ confidence interval (CI) [1.04, 2.38]. Only the association of best friend and father doing sport every week and playing sport with parents remained significantly associated with sufficient MVPA of adolescents in mutually adjusted model (Table 2, Model 2). Adolescents reporting a best friend doing sport every week have 1.7 higher chance to report MVPA 7 days per week (95\% 
Table 1

Sample description - frequencies (3,012 Slovak adolescents aged 12.5-16.0 years approached in 2014 within HBSC study)

\begin{tabular}{lrr}
\hline & Frequency, $n(\%)$ & Missing data, $n(\%)$ \\
\hline Boys & $1,512(50.2)$ & $33(1.1)$ \\
Sufficient MVPA & $668(22.4)$ & $125(4.2)$ \\
Father does sport every week & $990(34.3)$ & $77(2.6)$ \\
Mother does sport every week & $966(32.9)$ & $41(1.4)$ \\
Best friend does sport every week & $1,957(65.9)$ & $146(4.8)$ \\
Play sport with parents & & \\
$\quad$ at least once a week & $985(27.4)$ & \\
$\quad$ less often & $909(31.7)$ & \\
$\quad$ never & $1,172(40.9)$ & \\
Go for walk with parents & & \\
$\quad$ at least once a week & $1,093(38.2)$ & \\
less often & $1,080(37.7)$ & \\
never & $690(24.1)$ & \\
\hline
\end{tabular}

Note. $\quad$ MVPA = moderate-to-vigorous physical activity.

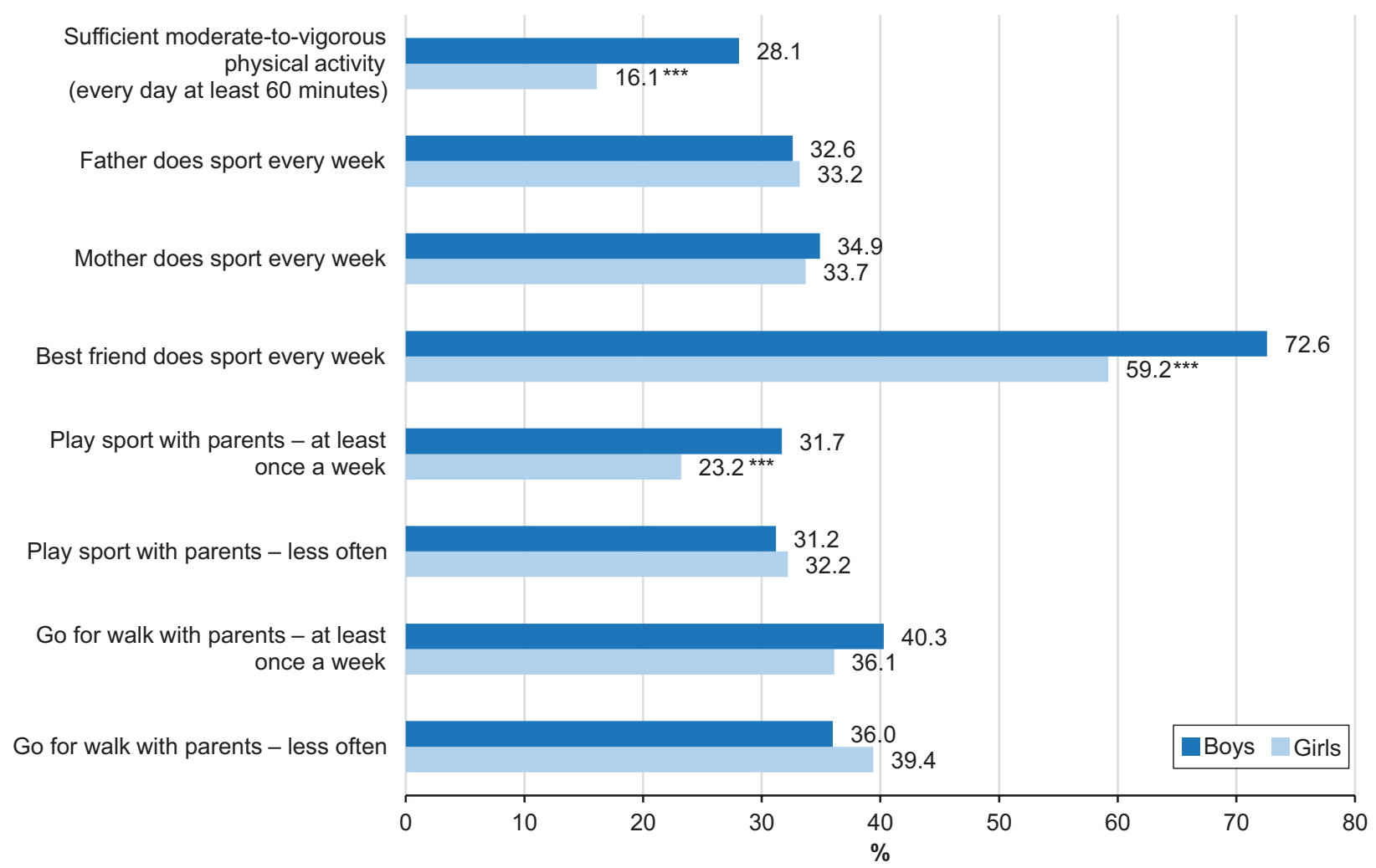

Figure 1. Gender differences in selected variables, prevalence in \% (3,012 Slovak adolescents aged 12.5-6.0 years, $50.2 \%$ boys, approached in 2014 within HBSC study, $* * * p<.001)$. 
Table 2

The association between potential parental and peers' correlates, and sufficient moderate-to-vigorous physical activity of adolescents, logistic regression (3,012 Slovak adolescents aged 12.5-16.0 years, 50.2\% boys, approached in 2014 within HBSC study)

\begin{tabular}{|c|c|c|c|c|c|c|}
\hline & \multicolumn{2}{|c|}{ Model 1} & \multicolumn{2}{|c|}{ Model 2} & \multicolumn{2}{|c|}{ Model 3} \\
\hline & $O R$ & $95 \% \mathrm{CI}$ & $O R$ & $95 \% \mathrm{CI}$ & $O R$ & $95 \% \mathrm{CI}$ \\
\hline \multicolumn{7}{|l|}{ Father } \\
\hline does sport every week & $1.67 * * *$ & {$[1.39,2.00]$} & $1.28^{*}$ & {$[1.04,1.59]$} & $1.34^{*}$ & {$[1.07,1.67]$} \\
\hline less than every week & 1 & & 1 & & 1 & \\
\hline \multicolumn{7}{|l|}{ Mother } \\
\hline does sport every week & $1.59 * * *$ & {$[1.32,1.91]$} & 1.21 & {$[0.98,1.50]$} & 1.09 & {$[0.87,1.36]$} \\
\hline less than every week & 1 & & 1 & & 1 & \\
\hline \multicolumn{7}{|l|}{ Best friend } \\
\hline does sport every week & $1.97 * * *$ & {$[1.64,2.36]$} & $1.69 * * *$ & {$[1.36,2.11]$} & $1.74 * * *$ & {$[1.38,2.19]$} \\
\hline less than every week & 1 & & 1 & & 1 & \\
\hline \multicolumn{7}{|l|}{ Play sport with parents } \\
\hline at least once a week & $1.90 * * *$ & {$[1.53,2.36]$} & $1.45^{* *}$ & {$[1.10,1.91]$} & 1.05 & {$[0.78,1.41]$} \\
\hline less often & $1.25^{*}$ & {$[1.00,1.56]$} & 1.24 & {$[0.96,1.59]$} & 0.78 & {$[0.58,1.04]$} \\
\hline never & 1 & & 1 & & 1 & \\
\hline \multicolumn{7}{|l|}{ Go for walk with parents } \\
\hline at least once a week & $1.47 * *$ & {$[1.17,1.86]$} & 1.10 & {$[0.83,1.45]$} & 1.35 & {$[1.01,1.80]$} \\
\hline less often & 0.91 & {$[0.71,1.61]$} & 0.76 & {$[0.58,1.01]$} & 1.06 & {$[0.81,1.39]$} \\
\hline never & 1 & & 1 & & 1 & \\
\hline
\end{tabular}

Note. Model 1 = each variable separately adjusted on gender; Model $2=$ all parental and peers' correlates adjusted on gender; Model $3=$ all parental and peers' correlates adjusted on gender, age and family affluence. $O R=$ odds ratio; $\mathrm{CI}=$ confidence interval. ${ }^{*} p<.05, * * p<.01, * * * p .001$.

CI [1.36, 2.11]). Adolescents with active fathers (doing sport weekly) have 1.3 higher chance to report MVPA 7 days per week $(95 \% \mathrm{CI}[1.04,1.59])$ in comparison to their peers with less active fathers. Playing sport with parents at least once a week increases the chance of adolescents to report sufficient MVPA 1.5 times more $(95 \%$ CI $[1.10,1.91])$ in comparison to their peers not having such experience. The father's and best friend's role behaviour remained significant after adjusting on age and family affluence, while playing sport with parents did not (Table 2, Model 3).

\section{Discussion}

The aim of the study was to assess the association between potential parental and peer correlates and PARC among 13-16 years old Slovak adolescents. Only one fifth of adolescents were meeting the PA guidelines. There were observed gender differences in variables such as sufficient MVPA, best friend doing sport every week and playing sport with parents. All explored variables representing potential parental and peers' correlates were significantly associated with sufficient MVPA of adolescents. The mutually adjusted model revealed the association between sufficient MVPA of adolescents and following variables: father doing sport every week, best friend doing sport every week and playing sport with parents.

The low level of PARC among Slovak adolescents (78\% of adolescents are not sufficiently physically active) corresponds with the prevalence of PARC in other countries worldwide (Hallal et al., 2012; Sigmundová et al., 2014). This finding is alarming since PA in adolescence contributes to the epidemic of non-communicable diseases in adulthood (Sawyer et al., 2012).

Higher prevalence of sufficient MVPA among boys $(28.1 \%)$ than among girls $(16.1 \%)$ in Slovak adolescents is in line with findings from other countries (Colley et al., 2017; Sirard et al., 2013), and supports strong evidence about gender differences in PA levels of adolescents (Hallal et al., 2012; Van Hecke et al., 2016). These differences may be related to advanced pubertal maturation of adolescent girls compared with boys, though the relative importance of biological and environmental influences on child and adolescent PA remains unclear and should be targeted in future research (Farooq et al., 2018; Sabiston \& Crocker, 2008; Slater \& Tiggemann, 2011). 


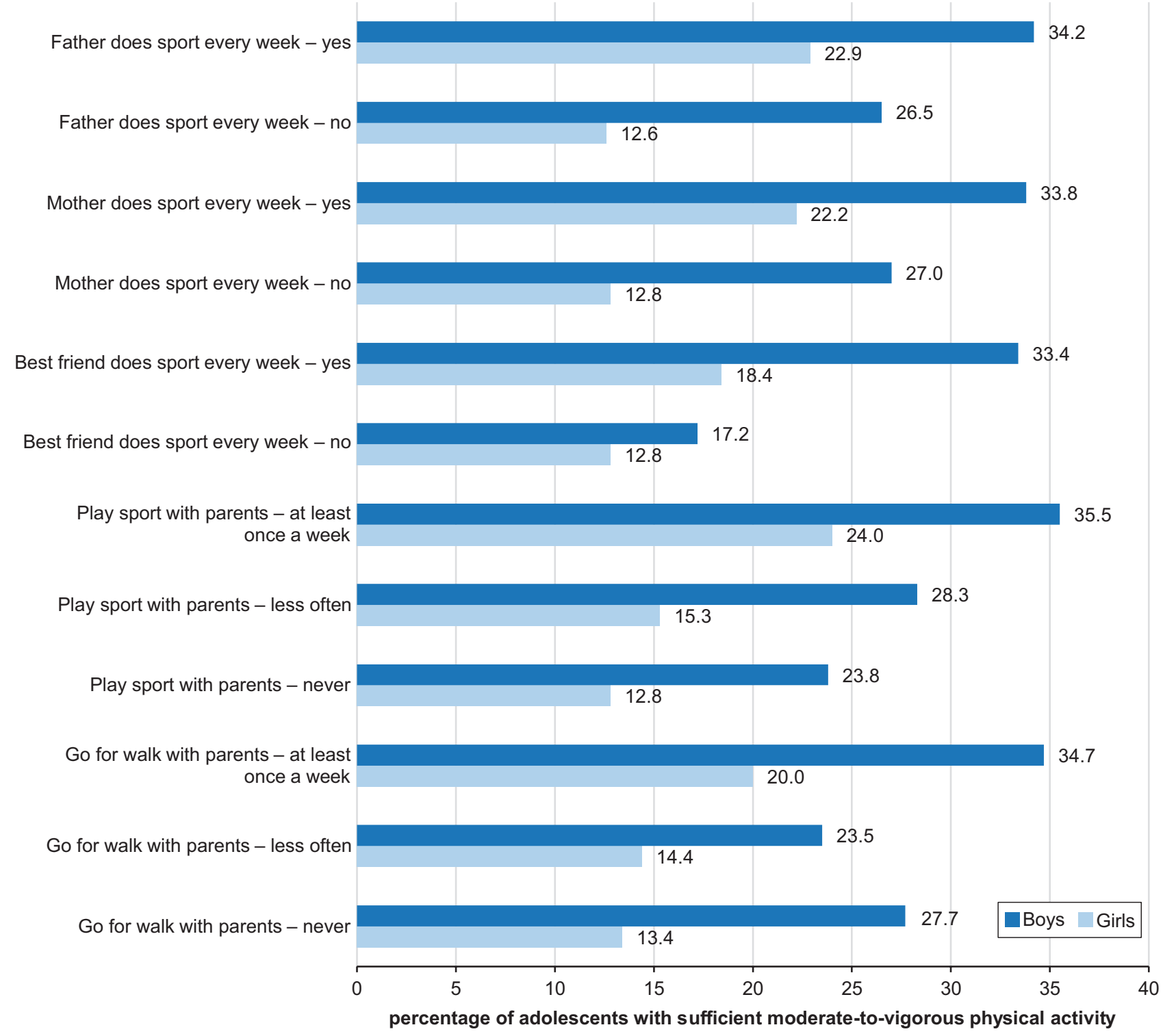

Figure 2. Relative frequency of selected variables in adolescents with sufficient moderate-to-vigorous physical activity.

Contrary to previous research (Sabiston \& Crocker, 2008; Sirard et al., 2013), boys reported more peer modelling (best friend doing sport every week) and tangible conditional parental support (playing sport together) compared to girls. As mentioned with previous variable (MVPA), gender differences in social factors of adolescents' PA should be targeted in future studies so that intervention strategies can be appropriately tailored (Sabiston \& Crocker, 2008).

Even though there were gender differences in prevalence of PA, as well as in prevalence of parental support (playing sport with parents) and peer modelling (best friend doing sport), only one interaction of the effect of each parental and peer correlate with gender on MVPA was found significant: the association between best friend doing sport every week and sufficient MVPA was significantly steeper/stronger in boys in comparison to girls. In other words, with one exception, there were no gender differences in association to parental and peer correlated with sufficient MVPA.

Our findings about positive association between parental PA and adolescents' PA is in line with previous findings (Yao \& Rhodes, 2015), but stronger association with paternal PA for both genders is in contrary to some studies (Jacobi et al., 2011; Seabra, Mendonça, Göring, \& Thomis, 2008). This inconsistence between findings of different studies can be explained by many reasons, e.g., by different measures used to assess parent and child PA (Schoeppe, Liersch, Röbl, Krauth, \& Walter, 2016). However, a fathers' PA was positively associated with child's PA by recent review of literature from 2005-2015 (Neshteruk, Nezami, Nino-Tapias, Davison, \& Ward, 2017), and there were already implemented an effective father-child-centred 
PA intervention (Morgan et al., 2015; Schoeppe et al., 2016). PA may be an important strategy for fathers to become involved in lifestyle change with their children as, compared to mothers, fathers traditionally tend to be comfortable engaging in PA with their children (Arlinghaus \& Johnston, 2017).

Going for a walk together and playing sport together were associated with sufficient MVPA which is in line with previous findings about positive association between tangible conditional parental support (doing activity together) and children's PA (Beets, Cardinal, \& Alderman, 2010). The stronger association between sufficient MVPA with playing sport together could be maybe associated with stronger association between sufficient MVPA and paternal PA, but since we did not discriminate between fathers and mothers in tangible parental support, it is difficult to say so.

According to adolescents in our sample, $65.7 \%$ of fathers and $67.1 \%$ of mothers are not doing sport every week, and $72.6 \%$ of adolescents do play sport with parents less often than once a week or do not play it at all. These numbers suggest that to increase children's and adolescents' PA levels it may be fruitful to focus on improving the MVPA among the whole family, including both parents (Fuemmeler, Anderson, \& Mâsse, 2011). Findings about the positive associations between the parental PA and support with children's and adolescents' PA, and existence of some, although limited, evidence of parent-child interventions effectiveness, would support that kind of focus.

Another factor found to be positively associated with adolescents' PA in our study is a best friend's PA. This finding is in line with substantial scientific evidence - 30 from 35 studies found that children's PA is associated with PA of their friends - suggesting that individuals may be guided by their friends' behaviour (Maturo \& Cunningham, 2013). As conclude Best, Ball, Zarnowiecki, Stanley, and Dollman (2017), peers influence children's PA most consistently through encouragement and positive modelling. Having peers that promote PA involvement and the perception that one's peers are open to PA were found to be linked with efficacious beliefs of one's ability to overcome potential barriers to participating in PA (Fitzgerald et al., 2012).

\section{Strengths and limitations of the study}

\section{Strengths of the study}

The main strength of the study is its cross-sectional design based on a representative sample of Slovak adolescents. This design allowed us to identify social correlates of Slovak adolescents' PARC. Research to identify correlates has both practical and theoretical uses. Practically, correlational studies generate hypotheses about possible causal relationships and about potential mediators that can be targeted in intervention studies. Theoretically, correlational studies could test predictions derived from theory and produce results that eventually lead to modifications in theories (Bauman, Sallis, Dzewaltowski, \& Owen, 2002).

\section{Limitations of the study}

The study limitation is the subjective method of measuring PA which is considered to be less accurate comparing to objective monitoring even though the latter has its own limitations (Atkin, Van Sluijs, Dollman, Taylor, \& Stanley, 2016). Subjective methods can provide rich contextual and descriptive data, but are vulnerable to memory limitations and in some cases over-reporting of some activities and in other instances under-reporting of incidental PA, especially walking (Dollman et al., 2009). However, due to the cross-sectional design of our study and available resources, the self-report consisting of one question was the only feasible method to be used (Chinapaw, Mokkink, van Poppel, van Mechelen, \& Terwee, 2010) even though we do recognise its limitations in comparison to instruments consisting of several questions (e.g., IPAQ).

\section{Conclusion}

We assessed the association between potential parental and peers' correlates and PARC among 13-16 years old Slovak adolescents. Association of a best friend and father doing sport every week and playing sport with parents was significantly associated with PARC of adolescents. These results indicate that best friends and fathers may play a role in the PA behaviour of adolescents through behaviour modelling, and parents in general through tangible parental support (playing sport with children).

\section{Acknowledgments}

The study was supported by Scientific Grant Agency of the Slovak Republic via VEGA 1/0427/17.

\section{Conflict of interest}

There were no conflicts of interest.

\section{References}

Arlinghaus, K. R., \& Johnston, C. A. (2017). Engaging fathers in the promotion of healthy lifestyle behaviors. American Journal of Lifestyle Medicine, 11, 216-219. 
Atkin, A. J., van Sluijs, E. M. F., Dollman, J., Taylor, W. C., \& Stanley, R. M. (2016). Identifying correlates and determinants of physical activity in youth: How can we advance the field? Preventive Medicine, 87, 167-169.

Badura P., Madarasova Geckova A., Sigmundova D., van Dijk J. P., \& Reijneveld S. A. (2015). When children play, they feel better: Organized activity participation and health in adolescents. BMC Public Health, 15, 1090.

Bauman, A. E., Sallis, J. F., Dzewaltowski, D. A., \& Owen, N. (2002). Toward a better understanding of the influences on physical activity. The role of determinants, correlates, casual variables, mediators, moderators, and confounders. American Journal of Preventive Medicine, 23(2 Suppl. 1), 5-14.

Beets, M. W., Cardinal, B. J., \& Alderman, B. L. (2010). Parental social support and the physical activity-related behaviors of youth: A review. Health Education \& Behavior, 37, 621-644.

Best, K., Ball, K., Zarnowiecki, D., Stanley, R., \& Dollman, J. (2017). In search of consistent predictors of children's physical activity. International Journal of Environmental Research and Public Health, 14, 1258.

Biddle, S. J. H., \& Mutrie, E. (2008). Psychology of physical activity. Determinants, well-being and interventions (2nd ed.). New York, NY: Routledge.

Brindova, D., Dankulincova Veselska, Z., Klein, D., Hamrik, Z., Sigmundova, D., van Dijk J. P., ... Madarasova Geckova, A. (2015). Is the association between screen-based behaviour and health complaints among adolescents moderated by physical activity? International Journal of Public Health, 60, 139-145.

Brooks, F., Magnusson, J., Klemera, E., Spencer, N., \& Morgan, A. (2011). HBSC England National Report: Health Behaviour in School-aged Children (HBSC): World Health Organization collaborative cross national study. Hertfordshire, United Kingdom: University of Hertfordshire.

Cheng, A. L., Mendonça, G., \& Farias Júnior, J. C. (2014). Physical activity in adolescents: Analysis of the social influence of parents and friends. Jornal de Pediatria, 90, $35-41$.

Chinapaw, M. J., Mokkink, L. B., van Poppel, M. N., van Mechelen, W., \& Terwee, C. B. (2010). Physical activity questionnaires for youth: A systematic review of measurement properties. Sports Medicine, 40, 539-563.

Colley, R. C., Carson, V., Garriguet, D., Janssen, I., Roberts, K. C., \& Tremblay, M. S. (2017). Physical activity of Canadian children and youth, 2007 to 2015. Health Reports, 28(10), 8-16.

Dollman, J., Okely, A. D., Hardy, L., Timperio, A., Salmon, J., \& Hills, A. P. (2009). A hitchhiker's guide to assessing young people's physical activity: Deciding what method to use. Journal of Science and Medicine in Sport, 12, 518-525.

Dumith, S. C., Gigante, D. P., Domingues, M. R., \& Kohl, H. W., III (2011). Physical activity change during adolescence: A systematic review and a pooled analysis. International Journal of Epidemiology, 40, 685-698.

Farooq, M. A., Parkinson, K. N., Adamson, A. J., Pearce, M. S., Reilly, J. K., Hughes, A. R., ... Reilly, J. J. (2018). Timing of the decline in physical activity in childhood and adolescence: Gateshead Millennium Cohort Study. British Journal of Sports Medicine, 52, 1002-1006.
Fitzgerald, A., Fitzgerald, N., \& Aherne, C. (2012). Do peers matter? A review of peer and/or friends' influence on physical activity among American adolescents. Journal of Adolescence, 35, 941-958.

Fuemmeler, B. F., Anderson, C. B., \& Mâsse, L. C. (2011). Parent-child relationship of directly measured physical activity. International Journal of Behavioral Nutrition and Physical Activity, 8, 17.

Hallal, P. C., Andersen, L. B., Bull, F. C., Guthold, R., Haskell, W., \& Ekelund, U. (2012). Global physical activity levels: Surveillance progress, pitfalls, and prospects. Lancet, 380, 247-257.

Hearst, M. O., Patnode, C. D., Sirard, J. R., Farbakhsh, K., \& Lytle, L. A. (2012). Multilevel predictors of adolescent physical activity: A longitudinal analysis. International Journal of Behavioral Nutrition and Physical Activity, 9, 8.

Iannotti, R. J., Janssen, I., Haug, E., Kololo, H., Annaheim, B., \& Borraccino, A. (2009). Interrelationships of adolescent physical activity, screen-based sedentary behaviour, and social and psychological health. International Journal of Public Health, 54(Suppl. 2), 191-198.

Inchley, J., Currie, D., Cosma, A., \& Samdal, O. (Eds.). (2018). Health Behaviour in School-aged Children (HBSC) Study Protocol: Background, methodology and mandatory items for the 2017/18 survey. St Andrews, United Kingdom: CAHRU.

Inchley, J., Currie, D., Young, T., Samdal, O., Torsheim, T., Augustson L., ... Molcho, M. (Eds.). (2016). Growing up unequal: Gender and socioeconomic differences in young people's health and well-being. Health Behaviour in Schoolaged Children (HBSC) study: International report from the 2013/2014 survey. Copenhagen, Denmark: World Health Organization, Regional Office for Europe.

Jacobi, D., Caille, A., Borys, J. M., Lommes, A., Couet, C., Charles, M., \& Oppert, J. (2011). Parent-offspring correlations in pedometer-assessed physical activity. PLOS ONE, 6(12), e29195.

Jaeschke, L., Steinbrecher, A., Luzak, A., Puggina, A., Aleksovska. K., \& Buck, C. (2017). Socio-cultural determinants of physical activity across the life course: A 'Determinants of Diet and Physical Activity' (DEDIPAC) umbrella systematic literature review. International Journal of Behavioral Nutrition and Physical Activity, 14, 173.

Janssen, I., \& LeBlanc, A. G. (2010). Systematic review of the health benefits of physical activity and fitness in school-aged children and youth. International Journal of Behavioral Nutrition and Physical Activity, 7, 40.

Kopcakova, J., Dankulincova Veselska, Z., Madarasova Geckova, A., Kalman, M., van Dijk, J. P., \& Reijneveld, S. A. (2015). Do motives to undertake physical activity relate to physical activity in adolescent boys and girls? International Journal of Environmental Research and Public Health, 12, 7656-7666.

Maturo, C. C., \& Cunningham, S. A. (2013). Influence of friends on children's physical activity: A review. American Journal of Public Health, 103, 23-38.

Morgan, P., Lubans, D., Young, M., Barnes, A., Eather, N., \& Pollock, E. (2015). Engaging dads to increase physical activity and well-being in girls: The DADEE (Dads And Daughters Exercising and Empowered) RCT. Journal of Science and Medicine in Sport, 195, e2-e32. 
Morrissey, J. L., Janz, K. F., Letuchy, E. M., Francis, S. L., \& Levy, S. M. (2015). The effect of family and friend support on physical activity through adolescence: A longitudinal study. International Journal of Behavioral Nutrition, 12, 103.

Neshteruk, C. D., Nezami, B. T., Nino-Tapias, G., Davison, K. K., \& Ward, D. S. (2017). The influence of fathers on children's physical activity: A review of the literature from 2009 to 2015. Preventive Medicine, 102, 12-19.

Prochaska, J. J., Sallis, J. F., \& Long, B. A. (2001). Physical activity screening measure for use with adolescents in primary care. Archives of Pediatric and Adolescent Medicine, 155, 554-559.

Reilly, J. J. (2016). When does it all go wrong? Longitudinal studies of changes in moderate-to-vigorous-intensity physical activity across childhood and adolescence. Journal of Exercise Science \& Fitness, 14, 1-6.

Sabiston, C. M., \& Crocker, P. R. E. (2008). Exploring selfperceptions and social influences as correlates of adolescent leisure-time physical activity. Journal of Sport \& Exercise Psychology, 30, 3-22.

Sawyer, S. M., Afifi, R. M., Bearinger, L. H., Blakemore, S., Dick, B., Ezeh, A. C., \& Patton, G. C. (2012). Adolescence: A foundation for future health. Lancet, 379, 1630-1640.

Schoeppe, S., Liersch, S., Röbl, M., Krauth, C., \& Walter, U. (2016). Mothers and fathers both matter: The positive influence of parental physical activity modeling on children's leisure-time physical activity. Pediatric Exercise Science, 28, 466-472.

Seabra, A. F., Mendonça, D. M., Göring, H. H., \& Thomis, M. A. (2008). Genetic and environmental factors in familial clustering in physical activity. European Journal of Epidemiology, 23, 205-211.

Sigmundová, D., Sigmund, E., Hamrik, Z., \& Kalman, M. (2014). Trends of overweight and obesity, physical activity and sedentary behaviour in Czech schoolchildren: HBSC study. European Journal of Public Health, 24, 210-215.

Sirard, J. R., Bruening, M., Wall, M. M., Eisenberg, M. E., Kim, S. K., \& Neumark-Sztainer, D. (2013). Physical activity and screen time in adolescents and their friends. American Journal of Preventive Medicine, 44, 48-55.

Slater, A., \& Tiggemann, M. (2011). Gender differences in adolescent sport participation, teasing, self-objectification and body image concerns. Journal of Adolescence, 34, 455-463.

Sweeting, H., West, P., \& Richards, M. (1998). Teenage family life, lifestyles and life changes: Associations with family structure, conflict with parents and joint family activity. International Journal of Law, Policy and the Family, 12, $15-46$.

Timperio, A. F., Van Stralen, M. M., Brug, J., Bere, E., Chinapaw, M. J. M., De Bourdeaudhuij, I., ... Te Velde, S. J. (2013). Direct and indirect associations between the family physical activity environment and sports participation among 10-12 year-old European children: Testing the EnRG framework in the ENERGY project. International Journal of Behavioral Nutrition and Physical Activity, 10, 15.

Van Hecke, L., Loyen, A., Verloigne, M., van der Ploeg, H. P., Lakerveld, J., Brug, J., ... Deforche, B. (2016). Variation in population levels of physical activity in European children and adolescents according to cross-European studies: A systematic literature review within DEDIPAC. International Journal of Behavioral Nutrition and Physical Activity, 13, 70.

World Health Organization. (2010). Global recommendations on physical activity for health. Geneva, Switzerland: Author. World Health Organization. (2018). Global action plan on physical activity 2018-2030: More active people for a healthier world. Geneva, Switzerland: Author.

Yao, C. A., \& Rhodes, R. E. (2015). Parental correlates in child and adolescent physical activity: A meta-analysis. International Journal of Behavioral Nutrition, 12, 10. 